\title{
Sustainable development in the era of digitalization: legal aspect
}

\author{
Svetlana Miroshnik ${ }^{1 *}$, Tatyana Vlasova $^{1}$, Vera Duel $^{1}$, Svetlana Zgorgelskaya ${ }^{1}$, and Tatyana \\ Lesovaya $^{1}$ \\ ${ }^{1}$ Russian State University of Justice, Novocheremushkinskay str, 69, 117418, Moscow, Russia
}

\begin{abstract}
The relevance of the topic of study is caused by the role and importance of the concept of sustainable development, the implementation of which allows creating a society, which, influenced by diverse internal and external factors, is capable of establishing a new equilibrium both within itself and in relation to the environment. The research object is public relations arising in the digitalization process. The purpose of the scientific research is to conduct systemic analysis of the impact of digitalization on sustainable development and the definition of the role of the law in the conditions of domination of constantly changing information and communication technologies. During the study, systemic, analytical, logical methods were used, as well as methods of interpretation of law, scientific forecasting, scientific intuition. It is concluded that the concept of sustainable development is aimed at creating an optimal, harmonious relationship of the needs, aspirations and interests of current and future generations on the basis of such fundamental principles of law as: equality, inadmissibility of abuse, prohibiting discrimination. The proposed characteristic made it possible to substantiate the diversity of the right to develop and subjective law. It has been proven that digitalization entails both positive and negative consequences. It is necessary to continue work on the international level of solutions, the implementation of which will allow achieving dynamic equilibrium.
\end{abstract}

\section{Introduction}

The concept of sustainable development received legal recognition both at the national and international levels. Even at the beginning of the seventies of the last century, scientists paid attention to the consequences of the "philosophy of consumption" dominated over the centuries and based on the formula "all for the good of a man, a man - the king of nature". The results of scientific and technical revolutions, which were catalysts for the essential growth of productive forces, under the influence of "resource thinking" gradually began not only to bring society the advantages and the momentary economic benefits, but also to exhaust the environment, create global environmental problems exacerbating every subsequent year. It is gratifying that the international community responded to the alarming signals of representatives of natural and social sciences. The United Nations has become a

\footnotetext{
* Corresponding author: miroshnik67@mail.ru
} 
center for discussion of planetary problems, which logically follows from its international legal status, goals and objectives enshrined in the UN Charter.

Under UN auspices, international conferences on the further development of humanity began to be held. In 1972, the Roman club published a report "Limits of growth", in which the limitations of natural resources, the tragic consequences of their use were substantiated, serious environmental degradation under the influence of human economic activity, the need and desirability of continuing technical progress in equilibrium were stated for the first time in terms of the systemic approach [1].

Thanks to the efforts of the UN member states, the legal basis was established necessary to solve problems, in particular:

- in 1980, the World Strategy for Conservation of Nature was developed, the leitmotif of which was the idea of the impossibility of reproduction of living natural resources without their protection, the need to use legal means in the process of managing natural resources;

- in 1982, the World Charter for Nature was adopted. States, given the importance of life in harmony with nature, recognized the environmental protection of the most important element in the field of socio-economic development [2].

The term "sustainable development" was introduced into the scientific and practical turnover by the World Commission on Environment and Development. In 1987, it presented a report on the need for adoption of such decisions, which would allow maintaining nature and providing natural resources to the current and future generations [3].

This understanding of sustainable development has become determining when making subsequent legal decisions by the international community. In 1992, the Rio Declaration on Environment and Development confirmed the importance of the right to development.

The UN Conference of 1992, which also took place in Rio de Janeiro, was a turning point in the development of the concept of sustainable development. The "Agenda for the XXI Century" was adopted there [4], which, in fact, is the program of a global partnership of states that are based on a three-pronged idea of inextricable relationship between economic development, social development, and environmental protection in order to ensure a safe and prosperous present and future. Scientific understanding of the realities and scientifically substantiated planning allowed the world community to determine the main activities, the results of which are significant for all mankind.

It was recognized that:

- humanity is capable of developing a steady dynamic nature;

- each person has the right to a favorable life;

- the needs of the modern person are diverse, but primary needs must be satisfied;

- human activity should be carried out taking into account the state and capabilities of the planet ecosystem.

The concept of sustainable development from an economic point of view is based on the works of the famous English economist, the Nobel Prize laureate John Richard Hicks. His understanding of the objectives of determining income is relevant to the present. The scientist believed that the definition of income makes it possible to find out how much he can consume without making himself poorer.

In 1994, R. Costanza and C. Folke clearly formulated the three problems interrelated with each other, the solution of which ensures sustainable development. They are as follows:

- the scale of the economy must comply with its environmental life support system (this ratio should be permanent),

- natural resources should be fairly distributed not only between the people of the current generation, but also between the current and future generations, between man and other biological species, 
- natural resources must be effectively distributed over time, which makes it possible to take into account the state of natural capital [5, P. 28-30].

It should be borne in mind that sustainable development cannot be reduced to conventional economic growth. The story has repeatedly confirmed that the growth rates themselves do not speak about the quality of human life, the degree of negative impact of economic activities on the state of the environment. The growth is characterized by quantitative indicators, sustainable development - by qualitative and quantitative data in their system relationship.

The environmental aspects of the concept of sustainable development, in our opinion, were laid by the famous Russian scientist V.I. Vernadsky. For the first time, he not only analyzed the essence of the system relations "man-nature", but also considered a system of human needs through the prism of the global space, creating a doctrine of the noosphere and the biosphere.

Sustainable development involves the stability of the environment. Humanity should build its life in such a way that natural systems do not lose their self-healing ability (and ideally, such a question should not even arise). A man is not the king of nature, but only one of the biological species whose live, like the life of other varieties, directly depends on the state of habitat. It's time when everyone should wonder not about what can make planet for us, but about what we can do for our planet. Nowadays, environmental problems arising in deep antiquity within the framework of relations between neighbors has been subjected to a public character affecting the interests of many countries [6, P. 13].

The concept of sustainable development in addition to the economic and environmental components includes social perspectives (Fig. 1).

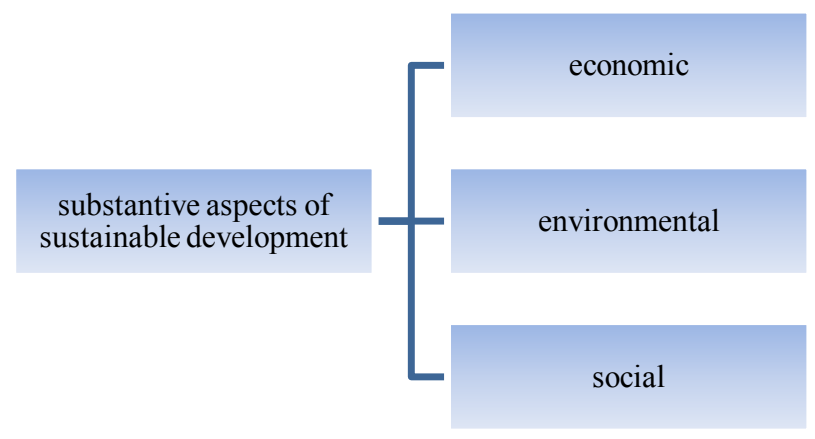

Fig. 1. Aspects of sustainable development.

As a rule, it is interpreted in a simpler way - as overcoming the difference in the levels of economic development, consequently, the standard of living between economically rich and poor states. It seems that this is only one of the aspects. In social terms, the concept of sustainable development is strategically aimed at creating a harmonious world without conflict and contradictions, tactically - at ensuring the right of every person to a certain minimum standard of living (unfortunately, it is not yet defined today, as the maximum allowed one in the conditions of exhaustion of natural resources).

The individual aspects of the concept of sustainable development became the subject of a number of scientific works, in which, in particular, the problems of ensuring the sustainable development of Tibet and other similar regions with extreme living conditions were considered [7], the promising topics of environmental research as a scientific basis of sustainable development were determined [8], an understanding of education as a key to the future quality of human life and the sustainability of the world was substantiated [9]. 
The concept of sustainable development was developed by scientific understanding of the results of scientific and technological progress and the assessment of their possible negative consequences. Today, humanity has entered the era of digitalization - the era of the new scientific and technological revolution. Previously conducted studies mainly concerned the possibilities of using information and communication technologies in various spheres of public life. In particular, the problems of digitalization of tourism [10] and agriculture [11] were considered, as well as the influence of new technologies on the environment [12] and sustainable production [13].

Legal aspects of the concept of sustainable development are not well developed. In this regard, the authors have a goal - to analyze the impact of digitalization on the concept of sustainable development, determine the role of law in the conditions of domination of information and communication technologies.

\section{Materials and methods}

In the context of this study, the concept of sustainable development is understood as a system of views on the fate of man, society, nature in their inextricable relationship.

A clear definition of the concept (first of all, the achievement of terminological unity as the basis of the concept) allows determining the strategy of specific actions.

This definition complies with scientifically based integrative legalism, which has become the methodological basis for scientific searches aimed at understanding the legal reality and the development of new areas of sustainable development. The authors of this study proceeded from understanding of:

- the right of both the totality of the principles and norms contained in a single, developing multi-level system of forms of national and international law implemented in the state;

- the source of the right as the basis for the occurrence of principles and norms of law;

- the forms of law as an external expression and registration of principles and norms of law;

- the diversity of the forms of law (regulatory legal acts, law treaties, legal customs, religious texts, legal doctrine, judicial precedents);

- the law-making as a type of legal activity for adoption, changing or canceling the principles and norms of law;

- the diversity of types of law-making (law-making, regulatory law-making, municipal law-making, contractual law-making, local law-making).

Used systemic approach and methods of interpretation of law (in particular, the interpretation of international law forms) made it possible to take into account the features of the legal registration of the concept of sustainable development at international and national levels, to study the forms of interaction between international and national law, to determine their development trends.

An analytical method made it possible to study digitalization processes, methods of deduction and induction - their possible positive and negative consequences for present and future generations. The achievement of the set goal was also promoted by scientific intuition, which is the unity of sensual and rational. Assessment of the state of the "network society", its possible qualitative and quantitative transformations, in some cases, was formed by reflection in consciousness of more or less unconscious.

Systemic and logical methods, methods of scientific forecasting allowed not only substantiating the understanding of digitalization as a factor of sustainable development, proving the increasing importance of law in the new conditions of the domination of information and communication technologies as a universal behavior regulator, but also 
proposing recommendations for overcoming and preventing negative trends that impede the effective implementation of the concepts of sustainable development.

\section{Results}

The concept of sustainable development implies, on the one hand, determining the urgent needs of humanity, and on the other, the awareness of the limited natural resources, the objective impossibility of the environment to satisfy the exorbitant demands of humanity. Accordingly, it is aimed at developing the optimal relationship between the needs, aspirations and interests of current and future generations on the basis of such general principles of law as: equality, inadmissibility of abuse of the right, prohibiting discrimination.

In the legal context, the concept of sustainable development can be characterized as follows. First, this concept has a planetary character, it expresses the opinion of the entire global community, which recognizes that no country can alone achieve sustainable development goals. Secondly, it is built on a systemic approach that determines the need for integration into a single whole environmental, economic, and social measurements and intentions based on existing and new scientific approaches. Sustainable development is impossible without science as an extremely important component in search of possible ways to solve the vital problems of humanity. Thirdly, this concept is open, naturally developing by the efforts of the global community. Nowadays, its development vectors define the goals and objectives adopted at the Seventieth session of the UN General Assembly in 2015. "Transformation of our world: Agenda in the field of sustainable development for the period up to 2030" provides for the achievement of seventeen of sustainable development goals and 169 tasks having a universal, complex, indivisible nature that ensure the balance of all three components of sustainable development: economic, social and environmental [14]. Fourthly, the only and universal means of implementing the concept is the law.

The rod element of the concept of sustainable development is the right to development, which have a special legal nature, not identical to the nature of subjective law (Fig. 2).

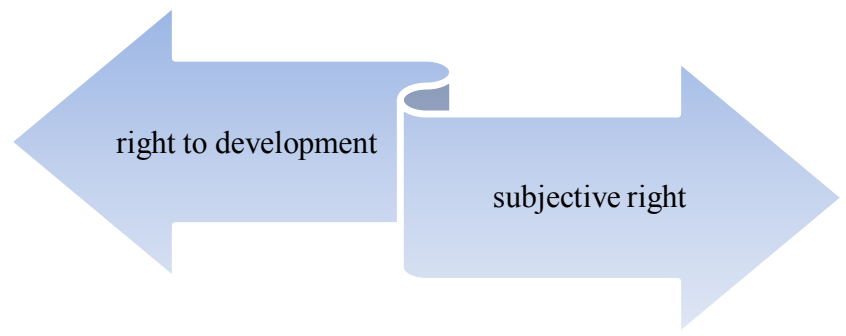

Fig. 2. The ratio of concepts.

In accordance with the Rio Declaration on Environment and Development, the right to development "should be observed in such a way as to adequately satisfy the needs of current and future generations in the fields of development and the environment" [15]. Accordingly, the right to development acts as a generalized legal category that simultaneously combines the measure of possible and the measure of due behavior. Its content determines the right of a person to live in good health and work in harmony with nature. This system-forming right corresponds to a whole range of responsibilities - 
common to all states and other entities of law, on the one hand, and differentiated depending on the degree of negative impact on the environment, the volume and nature of the technologies and financial resources they have.

\section{Discussion}

The term "scientific and technical revolution" is not often found in modern scientific papers. It arose in the framework of the Marxist tradition in order to proceed the advantages of socialism capable of not only to connect science and technique, science and production, but also to manage such complex processes in order to approximate the communist future. The collapse of the USSR, perceived by many as the crisis of Marxism, led to the emergence of such neutral categories in scientific studies as: "scientific and technical development", "scientific and technical progress". In our opinion, such a replacement is invalid. The term "scientific and technical revolution" is the process of radical changes in science, its transformation into a leading factor of production, which allowed qualitative change in the state of productive forces. That is why John Desmond Bernal was absolutely right (one of the creators of the concept of the scientific and technical revolution), noting the importance of changes, their revolutionary status [16].

Today we entered a new era. We are witnesses of fundamental changes in many areas of life. They became possible due to the emergence and rapid dissemination of information and communication technologies, which allowed transferring the world economy and social communication on a qualitatively new stage of development. The economic factor played its crucial role.

Transformations of society, states, personality are so large-scale that we can talk about the occurrence of a new stage of interaction of science and society - the stage of the scientific and technological revolution characterized by non-alternative (so far) domination of constantly modifying information and communication technologies.

Digital technologies have become an important human life satellite. New features of the big data processing have opened up. The most important area of the state policy of many countries was the support of the digital economy - knowledge economy. "The digital transformation has led to a change in business models of many traditional market participants. There were new participants and new markets" [17, P. 37-55]. The emerging digital platforms allowed solving the "service paradox". Thanks to them, business structures were able to simultaneously expand the number of services provided and improve their quality [18, P. 54-65]. A new world of digital financial services has opened up, which makes it possible to increase the efficiency of collecting fiscal payments and strengthen the struggle with illegal financial flows [19, P. 456-464]. New digital technologies turned out to be effective in solving issues of tactical and strategic planning. They became an "important tool in the fight against the spread of COVID-19" [20].

It should be borne in mind that digitalization is not only the transformation of the economy and law, the development and application of information and communication technologies in practical activity. There are more depth processes for the formation of a new digital culture, digital legal awareness (at the same time, the emergence of digital deformations of legal consciousness), new models of interaction in society (Fig. 3).

Digitalization helps a person to solve complex tasks, freeing up his time, providing the opportunity to work in creative activity, self-development and self-education, science and art, sports - those activities that do not imply the use of natural resources on a huge scale, do not entail a violation of the rhythms of the life of ecosystems. In the Roman report of 1972, it was emphasized that it was precisely such activities that could be carried out infinitely [1]. 


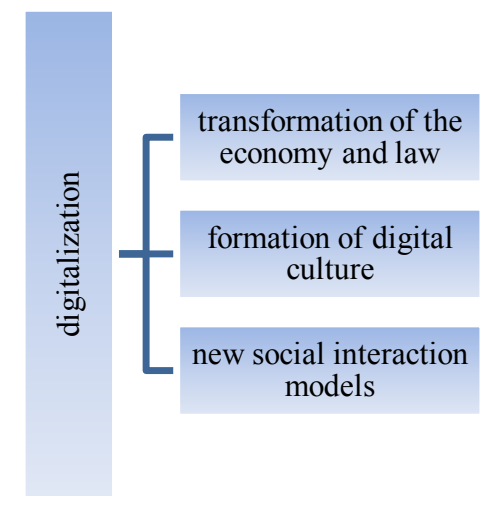

Fig. 3. The effect of digitalization.

The development of digital technologies is not only one of the derivatives of economic development, this is one "of derived progress in the implementation of rights and fundamental freedoms" [21].

At the same time, digitalization gave rise to a number of problems requiring serious scientific understanding. Lorna McGregor draws attention to the need for deep research on respect for human rights, developing new principles of accountability for the use of new technologies, since there is no clear understanding of the influence of artificial intelligence and other similar technologies on the quality of management, including public administration [22].

Subjects of law-making is not keeping pace with technological progress. New technologies appear much faster than the rules for their use or limitations. As Michiel A. Heldeweg reasonably considers, this is caused by the lack of sufficient knowledge about the consequences of the application of new technologies [6].

Digitalization changed the appearance of society. A network or digital society has become to form, significantly different from traditional society. First, it was created artificially, the scope of its existence is a virtual space that appeared due to information and communication technologies. Secondly, participation in the network "fraternity" does not depend on the presence or absence of legal personality. A full participant in the network society can be absolutely any subject of traditional law while carrying out certain conditions (for example: the presence of direct technical capabilities, registration and other conditions). Despite this, nowadays, network society turns out to be quantitatively much less than traditional one. Not all persons have a simple ability to connect to the global network. And some nations have already developed a common rule prohibiting to do it. As a result, a new gradation of a traditional society is divided into connected and unconnected ones. And this, according to M. Castells, is not a simple division, taking into account the fact that the main activity that organizes and controls the human activity throughout the planet is organized on the basis of global networks [23]. Capital acquires new opportunities for its impact on a planetary scale. The connected participants will win (compared to unconnected) - for them digital resources are available, which allow improving quality of their life. Information is becoming the main product, the main value. The era of the domination of the power of thought begins. But what will it lead to? This question remains open. The fact is that the gap between economically rich and developing states, secured and poor persons is now caused not only by the increase in population and capital gains (it is on these factors that attention in the report "Growth limits" was paid [1]), but also by the capabilities of a particular state, a specific subject to engage in the life of a network society. Scientists, in particular, pay attention to the close relationship of "information environmental awareness" and economic wealth [24]. 
The number of social contradictions is not decreasing, but only increasing. Social conflicts in traditional society are complemented by social conflicts within a network society and social conflicts between network and traditional society. The famous truth is once again confirmed: any good can be used both in the interests of a person and against him.

The validity of this conclusion is confirmed by the results of a number of serious economic research. So, according to Grigoryev L. and Pavlyushina V., who studied the development rates of 106 countries, in order to form sustainable tendencies to reduce inequality today, it is not enough to just double the GDP per capita. It is necessary to change the social system [25].

A coronavirus pandemic created significant difficulties for the implementation of the concept of sustainable development. It not only slowed down the pace of economic development, but also led to the need to search for new support measures due to the loss of the ability of the economies to function as self-sufficient systems [26]. "The hardest consequences and costs of a pandemic - humanitarian, social and financial - will be known only after time" [27].

The only way of salvation, in our opinion, is the use of the potential of the right as the only universal human behavior regulator. There is the dispute in the science about the ratio of digitalization and law. Without going into its essence, we will express your point of view.

Digitalization, in our opinion, does not change the nature of law. It allows us to see, analyze and use its new facets. Information and communication technologies are increasingly subordinate people to themselves. Programmers (creators of information and communication technologies), specialists (persons who can make changes to computer programs under the influence of various targets), and users (consumers) are involved in the network circuit. Relations between them are governed by algorithms created (or changed) by programmers and specialists - persons who have the necessary vocational competencies. Algorithms are unique. These are special rules of behavior that are capable of simultaneously performing the functions of technical and legal norms. In this regard, we propose to designate them as technical and legal norms. In addition to their dual nature, they differ in that they act within one or more digital shells - programs (accordingly, have a local character), can be created by any network participants.

In addition to technical and legal norms, the behavior of the participants in the network society is determined by the principles and norms of traditional law, which includes the subsystems of national and international law. At first glance it seems that the Internet is a global network that does not have spatial boundaries, and therefore not subject to legal impact and control by the state. The state is and will be a political organization of a public, sovereign and legitimate authorities, which has a conviction and coercion apparatus. Another thing is that the legal regulation of the Internet cannot and should not be a function of one state. The network society is based on horizontal connections, in accordance with which the importance of local rules of law is increasing. The state should not attempt to regulate all aspects of the network. Its tasks - to ensure the implementation and protection of rights and freedoms of a human and citizen in virtual space, to warn and prevent the offenses committed in a digital environment. Taking into account the specifics of the global network, the tasks are exceptionally challenging. Their solution is impossible without uniting the efforts of the whole global community, the agreed will of which should be reflected in relevant conventions, declarations, agreements.

Digitalization once again confirms the role and importance of law that includes the subsystem of international law and the national law subsystem (Fig. 4) 


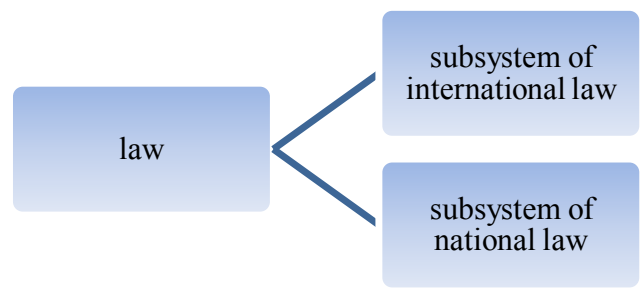

Fig. 4. The structure of law.

\section{Conclusions}

The concept of sustainable development arose at a certain stage of the development of society as a global economy, when it turned out to be impossible to ignore sharply exacerbated environmental problems as a result of a predatory attitude of a person to nature. The focus only on achieving economic efficiency did not give results. It did not allow advancing at the planned rate of universal prosperity and also created a real threat to everything alive on the planet.

It took a scientific understanding of the current situation, the development of a new concept of the image of current and future humanity being built on the basis of the trinity of the environmental, economic, and social components.

Information and communication technologies have discovered new opportunities and created new problems. On the one hand, they were able to accelerate the achievement of all 17 sustainable development goals [21]. The digital technology market is growing rapidly. Its volume for 2021 amounted to 350 billion dollars, it can grow up to 3.2 trillion dollars by 2025. On the other hand, not all countries ("the least developed countries and African countries south of Sahara") were ready to catch "this technological wave" [20]. The digital inequality appeared, which became a consequence of economic inequality and inequalities in knowledge. A new social structure of society was formed on a planetary scale, contradictions at the national and international levels increased.

It seems that a pandemic, with which humanity is fighting today, once again convincingly showed the significance and objective need to generate the ability to establish equilibrium as an answer to the impact of adverse external and internal factors. Nowadays, in the digitalization era, the concept of sustainable development requires its further development (Fig. 5).

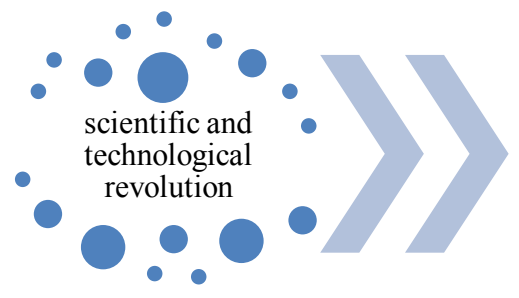

digitalization

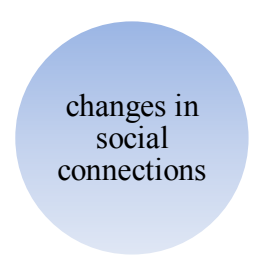

new understanding of the concept of sustainable development

Fig. 5. Digitalization and sustainable development. 
It is necessary to continue the work on the search for compromise solutions that allow humanity to successfully move forward.

To overcome the inequalities in the field of digital technology, new technologies are needed, which, on the one hand, provide high-quality and reliable access to the global network, and on the other - will be economical, and therefore available for developing countries.

In this regard, the United Nations recommends developing a regulatory framework, creating investment attractive regulatory regimens, expanding public-private partnerships, improving the quality of education, deepening international cooperation, including in relation to the issues of technology transfer on mutually favorable terms (Fig.6).

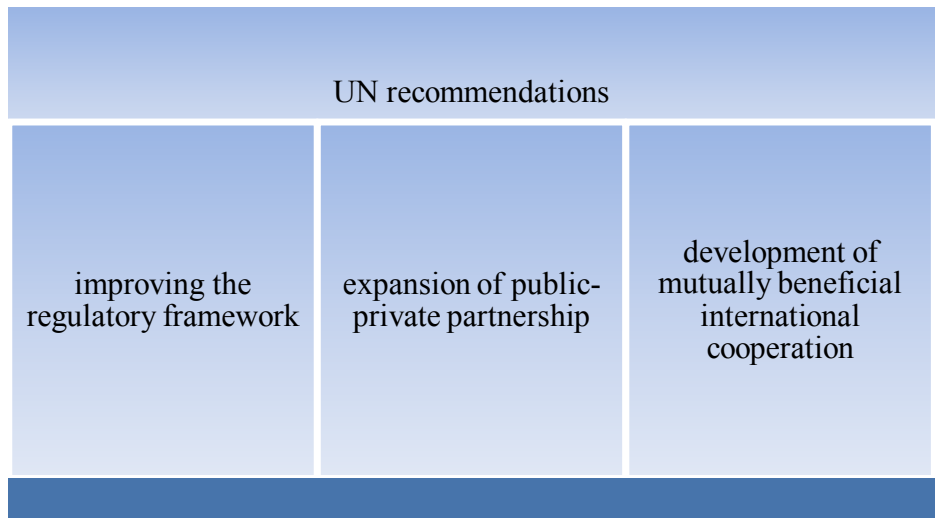

Fig. 6. Areas of combating digital inequality.

\section{References}

1. D.H. Meadows, D.L. Meadows, J. Randers, W.W. Berrens III, The Limits To Growth: a report for the Club of Rome's Project on the Predicament of Mankind (Universe Books, 1972)

2. Resolution adopted by the General Assembly on 28 October 1982 «World Charter for Nature» https://undocs.org/en/A/RES/37/7

3. Report of the World Commission on Environment and Development: Our Common Future // http://www.un-documents.net/our-common-future.pdf.

4. Report of United Nations Conference on Environment and Development, Rio de Janeiro 3-14 June (1992), V. I. Resolution Adopted the Conference. United Nations, New York (1993)

5. R. Costanza, C. Folke, Ecological Economics and Sustainable Development, Paper prepared for the International Experts Meeting for the Operationalization of the Economics of Sustainability. Manila, Philippines, July (1994)

6. M.A. Heldeweg, E3S Web of Conf. 4 International Conference on Sustainability Science (CSS2020) 249, 13 (2021) https://doi.org/10.1051/e3sconf/202124902001

7. Y. Zhao, D. Chen, J. Fan, Geography and Sustainability, 1, 275-283 (2020)

8. B. Fu, Y. Liu, Y. Li, C. Wang, Ch. Li, W. Jiang, T. Hua, W. Zhao, Geography and Sustainability, 4 (2021), doi: https://doi.org/10.1016/j.geosus.2021.04.001

9. N.C. Burbules, G. Fan, Ph. Repp, Geography and Sustainabiliry, 1, 2, 93-97 (2020) https://doi.org/10.1016/j.geosus.2020.05.001 
10. G. Li, E3S Web of Conf. International Conference on Tourism, Economy and Environmental Sustainability (TEES 2021), 251 (2021), 01059v(2021)

11. H.E. Bilalia, M.S. Allahyaribc, InformationProcessing in Agriculture, 5, 4, 456-464 (2018) https://doi.org/10.1016/j.inpa.2018.06.006

12. J. Wang, T. Xu, Environmental Impact Assessment Review, 89, 19690 (2021) https://doi.org/10.1016/j.eiar.2021.106590

13. S. Thide, Procedia CIRP, 98, 1-6 (2021) https://doi.org/10.1016/j.procir.2021.02.001

14. Transforming our world: the 2030 Agenda for Sustainable Development// https://undocs.org/en/A/70/L.1

15. Report of United Nations Conference on Environment and Development, Rio de Janeiro 3-14 June 1992, Volume I. Resolution Adopted the Conference. United Nations, New York (1993)

16. J.D. Bernal, Science in History. Volume One (Cameron Accosiates, INC. New York, 1954)

17. A.E. Shastitko, Voprosy Ekonomiki, 6, 37-55 (2020) DOI 10.32609/0042-8736-20206-37-55

18. J. Cenamora, D. Rönnberg Sjödin, V. Parida, International Journal of Production Economics, 192, 54-65 (2017)

19. Resolution adopted by the General Assambley on 20 December 2018 «Promotion of international cooperation to combat illicit financial flows and strengthen good practices on assets return to foster sustainable development»

20. Technology and Innovation Report 20121 UNCTAD https://unctad.org/system/files/official-document/tir2020_en.pdf

21. Resolution adopted by the General Assambley on 20 December 2017 «Information and communication technologies for sustainable development» https://undocs.org/en/A/RES/72/200

22. L. McGregor, The European Journal of International Law, 29,1079-1085 (2018)

23. M. Castells, Communication Power (Oxford: Oxford University Press, 2018)

24. W. Shlomo, W. Hans, Journal of Economics, 4, 328-345 (2018)

25. L. Grigoryev, V. Pavlyushina, Russian Journal of Economics, 5, 46-66 (2019) DOI 10.32609/j.ruje.5.35485

26. M.V. Ershov, Voprosy Ekonomiki, 12, 5-23 (2020) DOI 10.32609/0042-8736-2020$12-5-23$

27. G.V. Kolodo, Voprosy Ekonomiki, 5, 25-44 (2020) DOI 10.32609/0042-8736-2020-5$25-44$ 